\title{
Patterns of palliative care consultation among patients with brain metastasis: an opportunity for radiation oncologists to facilitate earlier referral
}

\author{
David M. McDermott ${ }^{1}$, Ashlee Seldomridge ${ }^{2}$, Ashray Maniar ${ }^{3}$, Malcolm D. Mattes $^{4}$ \\ ${ }^{1}$ Department of Radiation Oncology, West Virginia University, Morgantown, WV, USA; ${ }^{2}$ West Virginia University School of Medicine, \\ Morgantown, WV, USA; ${ }^{3}$ Department of Internal Medicine, Oregon Health and Science University, Portland, OR, USA; ${ }^{4}$ Department of Radiation \\ Oncology, Rutgers Cancer Institute of New Jersey, New Brunswick, NJ, USA \\ Contributions: (I) Conception and design: MD Mattes; (II) Administrative support: MD Mattes; (III) Provision of study materials or patients: DM \\ McDermott, MD Mattes; (IV) Collection and assembly of data: DM McDermott, A Seldomridge, A Maniar; (V) Data analysis and interpretation: All \\ authors; (VI) Manuscript writing: All authors; (VII) Final approval of manuscript: All authors. \\ Correspondence to: Malcolm D. Mattes, MD. Department of Radiation Oncology, Rutgers Cancer Institute of New Jersey, 195 Little Albany Street, \\ New Brunswick, NJ 08901, USA. Email: malcolm.mattes@gmail.com.
}

Background: Early palliative care (PC) physician involvement alongside standard oncologic care has been
recommended by the American Society of Clinical Oncology (ASCO) guidelines for all advanced cancer
patients, although adherence to these guidelines is variable. Radiation oncologists (ROs) could help facilitate
early PC referral for patients treated with palliative radiation, particularly those with brain metastasis
(BRM), and the aim of this study was to evaluate the circumstances of PC referral at our institution to better
understand the multidisciplinary approaches to facilitate it. Methods: Patients diagnosed with BRM from non-small cell lung cancer (NSCLC) from 2012 to 2018 whose primary RO and MO were at our institution were reviewed. Overall survival and time to PC consultation from the first oncologic visit following BRM diagnosis was determined using the KaplanMeier method. Mann-Whitney U and Chi-Squared assessed for predictive factors for shorter time to PC consultation. For these factors, the overall survival, rate of PC consultation, and PC setting was used to determine utilization of early PC.

Results: Among 103 eligible patients, only 48\% underwent a PC consultation in their lifetime, with the initial evaluation being as an outpatient for $37 \%$, and within 1 month of death for $35 \%$. Median survival from BRM diagnosis was 9.0 months. The median time from oncologic appointment to PC referral was 2.8 months, and from initial PC consultation to death was 1.6 months. Only more recent BRM diagnosis (2016-2018 vs. 2012-2015) was associated with shorter time to PC consultation (1.0 vs. 5.6 months, $\mathrm{P}=0.013)$, increased $\mathrm{PC}$ consult rate $(60 \%$ vs. $42 \%, \mathrm{P}=0.105)$, and increased outpatient $\mathrm{PC}$ consultation $(56 \%$ vs. $26 \%, \mathrm{P}=0.037)$.

Conclusions: The majority of patients did not undergo early PC consultation, though utilization has improved over time. As ROs are commonly involved in BRM management, they may be in a position to proactively support early $\mathrm{PC}$ consultations in this patient population.

Keywords: Metastases; palliative care; radiation oncology; referral; lung cancer

Submitted Feb 20, 2020. Accepted for publication Jul 27, 2020.

doi: $10.21037 /$ apm-20-462

View this article at: http://dx.doi.org/10.21037/apm-20-462

^ ORCID: 0000-0002-1151-896X. 


\section{Introduction}

Palliative care (PC) is a medical discipline that focuses on maximizing quality-of-life for patients with a life limiting condition. PC physicians emphasize control of physical and mental symptoms such as pain, anxiety, and depression, and help patients engage in advance care planning in order to ensure that when their health status changes the care received corresponds with their goals and wishes. Since 2012, the American Society of Clinical Oncology (ASCO) has recommend early PC consultation alongside standard oncologic care within 8 weeks of diagnosis for all patients with advanced, life-limiting cancer, and/or life expectancy less than 24 months (1). This consensus guideline, which was updated in 2017 and incorporated into National Comprehensive Cancer Network (NCCN) guidelines as well $(2,3)$, was supported by eleven randomized trials showing a constellation of quality-of-life benefits, and in the case of non-small cell lung cancer (NSCLC), even a survival benefit (4-14).

Unfortunately, adherence to these guidelines is variable. For instance, patients with metastatic cancers enrolled with a large regional commercial health insurer had PC consultation rates of $49 \%$, which only increased as patients were closer to death (15). Similarly, a recent study of Medicare beneficiaries with hematologic malignancies showed that PC services were billed for less than $2 \%$ of patients within 30 days of death (16).

Less is known about early PC utilization among patients with specific types of metastases. For instance, early PC referral alongside standard oncologic care may be particularly valuable in patients with brain metastasis (BRM), which is often associated with short life expectancy and significant morbidity (17-19). BRM may also represent a unique opportunity for multidisciplinary facilitation of PC referral, given that unlike many patients with metastatic cancer, who are primarily managed by a medical oncologist (MO), patients with BRM are often also managed and closely followed by radiation oncologists (ROs) and neurosurgeons (18-19). In this study, we investigated the circumstances of PC referral among patients with BRM from NSCLC at our institution, in order to better understand the need for improved multidisciplinary approaches to facilitate early PC referral in this patient population. We hypothesize that since the updated ASCO guidelines have been published, PC consultation continues to be underutilized. We present the following article in accordance with the STROBE reporting checklist (available at http://dx.doi.org/10.21037/apm-20-462).

\section{Methods}

All patients diagnosed with BRM secondary to NSCLC at a single institution from 2012 to 2018 were screened for inclusion in this retrospective study. Patients were excluded if they underwent a PC consultation prior to BRM diagnosis $(\mathrm{n}=6)$, were diagnosed with leptomeningeal carcinomatosis at the time of their initial BRM diagnosis $(n=3)$, were not seen by a $\mathrm{RO}(\mathrm{n}=1)$, if their primary $\mathrm{MO}$ or $\mathrm{RO}$ at the time of initial BRM diagnosis were at another institution $(n=17)$, or if they did not follow-up at our institution after diagnosis of BRM $(n=53)$. We identified a total of 103 patients that met our inclusion criteria, among whom 49 underwent a PC consultation following their BRM diagnosis. Potential selection bias was minimized by evaluating the medical records of all patients who met the inclusion criteria within the study period.

PC consultation characteristics were compiled, including the date of referral, date of consultation, location of consultation, and reason for consultation. The time to PC referral was determined from the date the patient was seen by an oncologist (MO or RO) following their BRM diagnosis to the date a PC referral was placed. For their radiation treatment, patients underwent either adjuvant or definitive treatment with GammaKnife ${ }^{\mathrm{TM}}$ (Elekta $\mathrm{AB}$, Stockholm, Sweden) stereotactic radiosurgery (SRS), whole brain radiation treatment (WBRT), or both, with dosing consistent with NCCN guidelines (20). Whether or not a patient had undergone surgical resection of a BRM was also recorded. There was no missing data for any included patient for the variables of interest.

Descriptive statistics were used to summarize our findings. The Chi-squared test and Mann-Whitney $\mathrm{U}$ test were used to determine if any subgroups of patients were more likely to undergo PC referral. The Kaplan-Meier method was used to assess survival outcomes from the date of BRM diagnosis, and date of PC consultation, respectively, to the date of death or last follow-up. The log-rank test was used to compare the time to PC consultation, and survival, for subgroups of patients. Statistical analysis was performed using IBM SPSS version 24 (IBM cooperation, Armonk, NY, USA). Any $\mathrm{P}$ value less than 0.05 was considered statistically significant. This study was conducted in accordance with the Declaration of Helsinki (as revised in 2013). The study was approved by the institutional review board of West Virginia University (No. 1605130539), and 
Table 1 Baseline patient characteristics

\begin{tabular}{|c|c|}
\hline Characteristic & $\mathrm{N}[\%]$ \\
\hline \multicolumn{2}{|l|}{ Age } \\
\hline$\leq 65$ & $59[57]$ \\
\hline$>65$ & 44 [43] \\
\hline \multicolumn{2}{|l|}{ Gender } \\
\hline Male & $57[55]$ \\
\hline Female & $46[45]$ \\
\hline \multicolumn{2}{|l|}{ Karnofsky Performance Status } \\
\hline$\geq 70$ & 93 [90] \\
\hline$<70$ & $10[10]$ \\
\hline \multicolumn{2}{|l|}{ Extracranial disease control } \\
\hline Controlled & 33 [32] \\
\hline Uncontrolled & 70 [68] \\
\hline \multicolumn{2}{|l|}{ RPA class } \\
\hline I & 29 [28] \\
\hline II & 64 [62] \\
\hline III & $10[10]$ \\
\hline \multicolumn{2}{|c|}{ Initial number of brain metastases } \\
\hline 1 & 39 [38] \\
\hline $1-3$ & 71 [69] \\
\hline$>3$ & $32[31]$ \\
\hline \multicolumn{2}{|l|}{ Tumor histology } \\
\hline Adenocarcinoma & 75 [73] \\
\hline Squamous cell carcinoma & $19[18]$ \\
\hline Other & $9[9]$ \\
\hline \multicolumn{2}{|l|}{ EGFR mutation status } \\
\hline Positive & $11[11]$ \\
\hline Negative & $61[59]$ \\
\hline Unknown & 31 [30] \\
\hline \multicolumn{2}{|l|}{ ALK mutation status } \\
\hline Positive & $1[1]$ \\
\hline Negative & $72[70]$ \\
\hline Unknown & 30 [29] \\
\hline \multicolumn{2}{|l|}{ PD-L1 status } \\
\hline Positive ( $\geq 1 \%)$ & $18[17]$ \\
\hline Negative & $10[10]$ \\
\hline Unknown & 75 [73] \\
\hline
\end{tabular}

Table 1 (continued)
Table 1 (continued)

\begin{tabular}{lc}
\hline Characteristic & $\mathrm{N}[\%]$ \\
\hline Initial BRM directed treatment & $3[3]$ \\
Surgery & $12[12]$ \\
Surgery + WBRT & $17[17]$ \\
Surgery + SRS & $19[18]$ \\
WBRT & $51[49]$ \\
SRS & $1[1]$ \\
WBRT + SRS & \\
Number of BRM recurrences & $57[55]$ \\
0 & $31[30]$ \\
1 & $15[15]$ \\
$\geq 2$ &
\end{tabular}

RPA, recursive partitioning analysis; BRM, brain metastasis; WBRT, whole brain radiation therapy; SRS, stereotactic radiosurgery.

individual consent for this retrospective analysis was waived.

\section{Results}

The baseline characteristics of all 103 patients are outlined in Table 1. Nine different MOs, 8 ROs, 5 neurosurgeons, and 4 PC physicians were involved in their care. The median age of the study population was 64 years [interquartile range (IQR), 56-72 years]. The median Karnofsky Performance Score (KPS) was 80 (IQR, 70-90). The median size of the largest BRM was $2.0 \mathrm{~cm}$ (IQR, $1.0-3.0 \mathrm{~cm})$. A total of $75 \%$ of patients underwent SRS as a component of their BRM management. Fifty percent of patients underwent WBRT as a component of their BRM management, with 40 patients $(76.9 \%)$ receiving a dose of $30 \mathrm{~Gy}$ in 10 fractions, and 7 patients (13.4\%) not completing their prescribed WBRT course.

Forty-nine patients (48\%) underwent a PC consultation during their lifetime following their diagnosis of BRM, among which $63 \%$ took place in the inpatient setting and $37 \%$ in the outpatient setting. Forty patients (82\%) were referred by a MO, $8(16 \%)$ by an internal medicine physician, and 1 ( $2 \%$ ) by a RO. The reason for PC consultation as reported in the referring physician notes included pain/symptom management (63\%), decreased performance status (22\%), systemic disease progression $(22 \%)$, and intracranial disease progression (10\%). Fourteen 
patients $(27 \%)$ had a documented refusal of PC referral, though seven of these patients ultimately underwent PC consultation at a later point. Among all demographic variables from Table 1, PC consultation was significantly more likely only for patients with more than 3 BRMs (43\% vs. $20 \%, \mathrm{P}=0.048$ ), and for patients who underwent WBRT during their treatment course $(65 \%$ vs. $37 \%, \mathrm{P}<0.01)$.

The median follow-up was 43 months. The median survival from BRM diagnosis (for all patients) was 9.0 months (IQR, 3.7-23.5 months), and the median survival from PC consultation was 1.6 months (IQR, 0.55.4 months). There was no association between survival and whether the patient underwent a PC consultation in their lifetime $(\mathrm{P}=0.12)$, though patients that underwent an initial outpatient PC consultation had a longer median survival than those who underwent initial inpatient $\mathrm{PC}$ consultation (16 vs. 4.8 months, $\mathrm{P}<0.01$ ).

The median time to PC referral was 2.8 months (IQR, $0.5-9.4$ months). Twenty-one (43\%) of the PC consultations took place within 2 months of BRM diagnosis, though $67 \%$ of these took place in the inpatient setting, and the median survival for patients who had a PC referral within 2 months of BRM diagnosis was significantly lower compared to those who did not (2.9 vs. 13.0 months, $\mathrm{P}<0.01)$. Seventeen (35\%) of the PC consultations occurred within 1 month of death. Table 2 shows that the time to PC consultation was significantly shorter for patients who were older than age 65 , had a higher RPA class, or who were diagnosed with BRM more recently (2016-2018). Table 3 shows that of these factors, only BRM diagnosis from 2016 to 2018 was also associated with a higher percentage of outpatient PC consultations ( $56 \%$ vs. $26 \%, \mathrm{P}=0.037$ ), and a trend towards higher percentage of PC consultations overall $(60 \% v s$. $42 \%, \mathrm{P}=0.105)$.

\section{Discussion}

Since 2010, randomized evidence has supported the role of early PC physician involvement alongside standard oncologic care in the management of patients with metastatic NSCLC (21). Eleven additional randomized trials have shown a quality-of-life benefit for a variety of advanced malignancies (4-14). In 2012, ASCO consensus guidelines supported early PC consultation for any patient with advanced cancer, which has been reiterated in later guidelines from ASCO and the NCCN as well. However, at our institution the majority of patients since 2012 never had a PC consultation before their death, and only $37 \%$ of PC consultations took place in the outpatient setting, the more ideal location for an early PC consultation to take place, rather than in the inpatient setting when a patient is often decompensating and nearing death (22). Even among patients who had a PC consultation within 2 months of BRM diagnosis, our data suggests that the reason for it was not for early involvement alongside standard oncologic care, but rather because those patients had more aggressive disease with a very poor life expectancy. Overall, the median time from PC consultation was much closer to death for the average patient, than it was to diagnosis of BRM. However, there was an improvement over time, with patients diagnosed in 2016-2018 being more likely to have an initial outpatient PC consultation even though they were not necessarily living longer than the patients diagnosed from 2012 to 2015 . However, even in this more recent cohort, PC consultation still had not taken place for $40 \%$ of patients, and the initial PC consultation was still in the inpatient setting for $44 \%$ of patients.

The outcomes of this type of study are likely to be impacted by the culture of the physicians at a given institution, the availability of PC physicians at that institution, and the type of healthcare system in a given country. For instance, one retrospective study from Ireland reported a $100 \% \mathrm{PC}$ referral rate among patients with SCLC, two-thirds of which were within 1 month of diagnosis (23). The authors attributed their relative success to the PC team participating in multidisciplinary patient discussions, and the availability of advanced nurse practitioners to help facilitate establishing the patient with the PC team. Conversely, a survey of physicians caring for lung cancer patients at five New York City centers showed that approximately one-half of respondents referred less than $25 \%$ of their patients for PC consultation (24). Similar to our findings, a French institution reported that less than $40 \%$ of patients with BRM underwent PC consultation (25), and a retrospective study from Vanderbilt University showed that $68 \%$ of patients receiving WBRT for BRM underwent a PC consultation, the majority of which were in the inpatient setting, with $52 \%$ of patients dying within 1 month of PC referral (26).

NCCN and ASCO guidelines describe an optimal approach to early PC consultations, though much as many oncology treatment teams have variable referral patterns for early PC, PC physicians may have variable approaches to patient care. As such, a critical component to facilitating early PC referral may lie in building trust between the involved physicians through effective communication and 
Table 2 Time to palliative care referral

\begin{tabular}{|c|c|c|c|}
\hline Factor & Number of patients & Time (months), median (IQR) & $P$ value \\
\hline \multicolumn{4}{|l|}{ Age (years) } \\
\hline$\leq 65$ & 33 & $3.2(1.2-11.7)$ & 0.039 \\
\hline$>65$ & 16 & $0.5(0.1-6.9)$ & \\
\hline \multicolumn{4}{|l|}{ Gender } \\
\hline Female & 20 & $6.9(1.6-9.5)$ & \\
\hline \multicolumn{4}{|l|}{ PC consultation location } \\
\hline Inpatient & 31 & $2.1(0.5-8.4)$ & 0.633 \\
\hline Outpatient & 18 & $2.8(0.6-18.0)$ & \\
\hline Uncontrolled & 36 & $1.8(0.4-6.2)$ & \\
\hline \multicolumn{4}{|l|}{ RPA class } \\
\hline I & 11 & $9.5(2.1-20.1)$ & 0.049 \\
\hline II-III & 38 & $1.8(0.5-6.9)$ & \\
\hline \multicolumn{4}{|l|}{ Number of brain metastases } \\
\hline 1 & 18 & $2.9(1.8-9.4)$ & 0.356 \\
\hline$\geq 2$ & 31 & $1.6(0.4-9.5)$ & \\
\hline \multicolumn{4}{|l|}{ Surgery status } \\
\hline \multicolumn{4}{|l|}{ Year of BRM diagnosis } \\
\hline 2012-2015 & 31 & $5.6(0.8-20.0)$ & 0.013 \\
\hline 2016-2018 & 18 & $1.0(0.1-2.1)$ & \\
\hline
\end{tabular}

IQR, interquartile range; PC, palliative care; RPA, recursive partitioning analysis; BRM, Brain metastasis.

a shared understanding of the composition of these early PC consultations. Ideally, PC physicians and treating oncologists should all understand that these are referrals to support the patient and the oncology team, and not simply usher the patient towards hospice or away from cancerdirected therapies "prematurely" (27). It is our opinion that any institution that treats patients with cancer should work hard to build this trust among its providers to facilitate a more patient-centered approach to those diagnosed with a life-limiting condition than currently exists at the average US facility (28). Accreditation Council for Graduate Medical Education (ACGME) guidelines should also consider doing more to mandate cross-disciplinary education in these specialties (29), and overcome differences in perception of appropriate end-of-life care that may exist between oncologists and PC physicians (30). 
Table 3 Factors associated with shorter time to palliative care referral

\begin{tabular}{|c|c|c|c|c|c|c|c|c|}
\hline Factor & \multicolumn{2}{|c|}{ Time to PC referral } & \multicolumn{2}{|c|}{ Survival } & \multicolumn{2}{|c|}{ PC consult } & \multicolumn{2}{|l|}{ PC setting } \\
\hline \multicolumn{9}{|l|}{ Age (years) } \\
\hline$\leq 65$ & $3.2(1.2-11.7)$ & 0.039 & $10.8(4.6-26.0)$ & 0.163 & 56 vs. 44 & 0.049 & 42 vs. 58 & 0.235 \\
\hline$>65$ & $0.5(0.1-6.9)$ & & $7.0(2.9-20.4)$ & & 36 vs. 64 & & 25 vs. 75 & \\
\hline I & $9.5(2.1-20.1)$ & 0.049 & $20.4(9.0-38.8)$ & $<0.001$ & 38 vs. 62 & 0.220 & 36 vs. 64 & 0.977 \\
\hline II-III & $1.8(0.5-6.9)$ & & $7.4(3.3-15.1)$ & & 51 vs. 49 & & 37 vs. 63 & \\
\hline \multicolumn{9}{|c|}{ Year of BRM diagnosis } \\
\hline 2012-2015 & $5.6(0.8-20.0)$ & 0.013 & $9.3(4.4-21.7)$ & 0.692 & 42 vs. 58 & 0.105 & 26 vs. 74 & 0.037 \\
\hline WBRT & $0.8(0.4-5.6)$ & 0.062 & $4.9(1.9-10.8)$ & $<0.001$ & 58 vs. 42 & 0.163 & 26 vs. 74 & 0.229 \\
\hline SRS & $4.0(1.2-18.0)$ & & $10.8(4.8-26.1)$ & & 43 vs. 57 & & 43 vs. 57 & \\
\hline
\end{tabular}

IQR, interquartile range; PC, palliative care; RPA, recursive partitioning analysis; BRM, brain metastasis; WBRT, whole brain radiation therapy; SRS, stereotactic radiosurgery.

Among physicians who could refer a patient for early $\mathrm{PC}, \mathrm{MOs}$ are the most logical choice to do so given that they are typically the "primary" oncologist following metastatic cancer patients, and offer treatments that are most closely correlated to life expectancy. However, the premise of this study was that ROs are in a unique position to support early PC referral for a condition like BRM that is associated with a poor prognosis, and is nearly always evaluated and/or treated by ROs. Our findings suggest that for the majority of patients who did not undergo a PC consultation, the primary issue was that it was never offered, more so than patients refused. In either scenario, ROs could help encourage patients to take advantage of this evidence-based strategy. However, whether ROs should be considered responsible for adhering to this aspect of guidelines and facilitating PC referral has been debated. For instance, an important barrier to ROs referring patients for early PC may come from the MOs themselves, with recent data showing that many MOs are territorial of their role as the "primary" oncologist for incurable cancer patients and would not want others interfering with PC referrals without their permission $(31,32)$. Indeed, a national survey of ROs reported fear of upsetting MOs as the most important barrier to RO participation in advanced care planning (33). Whether ROs are even qualified to counsel patients on advanced care planning, prognosis, and disease course has been questioned by MOs (31). However, it is our opinion that for a condition like BRM, where life expectancy is wellstudied and understood (19), and an essential component of the decision of whether to administer radiotherapy in the first place (34), it is hard to argue that ROs are any less qualified than MOs. Furthermore, considering the potential morbidity associated with brain radiotherapy, additional neurocognitive and psychosocial support that PC teams can provide is likely to be very beneficial to this particular patient population (17). Interestingly, the one trial evaluating life expectancy predictions specifically in patients with BRM showed that neurosurgeons and ROs more accurately predicted long-term life expectancy than MOs (35).

Most physicians tend to be biased by optimism that their treatment(s) will be effective (36), and commonly over-estimate life expectancy as a result (37-39). For this reason, predictive indices based on clinical features have been developed to more objectively assess life expectancy, and any subspecialist could put those models to use $(40,41)$. Ideally, such validated indices should be prioritized over any individual physician's subjective assessments (42). While most MOs may have good intentions in withholding a PC referral from patients, multidisciplinary involvement to 
ensure that these evidence-based referrals take place is likely necessary if there is any chance of them routinely taking place.

The main limitation of this study is that it is a singleinstitution, retrospective experience with limited sample size. However, as we have described above, our findings are generally concordant with similar studies from the US as well as population data. Another limitation is that the timing of PC referral may hinge upon episodes of disease progression, whereas we considered only the first course of brain-directed radiotherapy and ignored the effect of other modalities (such as chemotherapy) or subsequent courses of radiotherapy in determining our study population. Finally, documentation of which PC referrals were truly made with the intention of early PC involvement alongside usual oncologic care was not readily available in the medical records, and instead our interpretation of the intention of PC referrals was based on surrogate endpoints such as the timing of the referral, the setting of the referral, and the prognosis of the patient for which the referral was made.

\section{Conclusions}

Early PC referral for patients with BRM from NSCLC at our institution is increasingly utilized, but still uncommon despite the involvement of multiple different providers, and current ASCO and NCCN consensus guidelines. ROs are in a position to proactively support early $\mathrm{PC}$ consultations in this patient population by facilitating improved communication with other members of the multidisciplinary team.

\section{Acknowledgments}

Meeting presentations: American Society for Radiation Oncology, Annual Meeting, September 2019. Chicago, IL. Funding: None.

\section{Footnote}

Reporting Checklist: The authors have completed the STROBE reporting checklist. Available at http://dx.doi. org/10.21037/apm-20-462

Data Sharing Statement: Available at http://dx.doi. org/10.21037/apm-20-462

Provenance and Peer Review: This article was commissioned by the Guest Editors (Edward Chow and Candice
Johnstone) for the series "Palliative Radiotherapy Column" published in Annals of Palliative Medicine. The article has undergone external peer review.

Conflicts of Interest: All authors have completed the ICMJE uniform disclosure form (available at http:// dx.doi.org/10.21037/apm-20-462). The series "Palliative Radiotherapy Column" was commissioned by the editorial office without any funding or sponsorship. The authors have no other conflicts of interest to declare.

Ethical Statement: The authors are accountable for all aspects of the work in ensuring that questions related to the accuracy or integrity of any part of the work are appropriately investigated and resolved. This study was conducted in accordance with the Declaration of Helsinki (as revised in 2013). The study was approved by the institutional review board of West Virginia University (No. 1605130539), and individual consent for this retrospective analysis was waived.

Open Access Statement: This is an Open Access article distributed in accordance with the Creative Commons Attribution-NonCommercial-NoDerivs 4.0 International License (CC BY-NC-ND 4.0), which permits the noncommercial replication and distribution of the article with the strict proviso that no changes or edits are made and the original work is properly cited (including links to both the formal publication through the relevant DOI and the license). See: https://creativecommons.org/licenses/by-nc-nd/4.0/.

\section{References}

1. Smith TJ, Temin S, Alesi ER, et al. American Society of Clinical Oncology provisional clinical opinion: The integration of palliative care into standard oncology care. J Clin Oncol 2012;30:880-7.

2. Ferrell BR, Temel JS, Temin S, et al. Integration of palliative care into standard oncology care: American Society of Clinical Oncology clinical practice guideline update. J Clin Oncol 2017;35:96-112.

3. National Comprehensive Cancer Network. Palliative Care (Version 2.2019). Accessed November 17, 2019. Available online: https://www.nccn.org/professionals/physician_gls/ pdf/palliative.pdf

4. Bakitas MA, Tosteson TD, Li Z, et al. Early versus delayed initiation of concurrent palliative oncology care: Patient outcomes in the ENABLE III randomized controlled trial. 
J Clin Oncol 2015;33:1438-45.

5. Chochinov HM, Kristjanson LJ, Breitbart W, et al. Effect of dignity therapy on distress and end-of-life experience in terminally ill patients: A randomised controlled trial. Lancet Oncol 2011;12:753-62.

6. Dionne-Odom JN, Azuero A, Lyons KD, et al. Benefits of early versus delayed palliative care to informal family caregivers of patients with advanced cancer: Outcomes from the ENABLE III randomized controlled trial. J Clin Oncol 2015;33:1446-52.

7. Dyar S, Lesperance M, Shannon R, et al. A nurse practitioner directed intervention improves the quality of life of patients with metastatic cancer: Results of a randomized pilot study. J Palliat Med 2012;15:890-5.

8. Ferrell B, Sun V, Hurria A, et al. Interdisciplinary palliative care for patients with lung cancer. J Pain Symptom Manage 2015;50:758-67.

9. Grudzen CR, Richardson LD, Johnson PN, et al. Emergency department-initiated palliative care in advanced cancer: A randomized clinical trial. JAMA Oncol 2016;2:591-8.

10. Higginson IJ, Bausewein C, Reilly CC, et al. An integrated palliative and respiratory care service for patients with advanced disease and refractory breathlessness: A randomised controlled trial. Lancet Respir Med 2014;2:979-87.

11. Hudson P, Trauer T, Kelly B, et al. Reducing the psychological distress of family caregivers of homebased palliative care patients: Short-term effects from a randomised controlled trial. Psychooncology 2013;22:1987-93.

12. Sun V, Grant M, Koczywas M, et al. Effectiveness of an interdisciplinary palliative care intervention for family caregivers in lung cancer. Cancer 2015;121:3737-45.

13. Uitdehaag MJ, van Putten PG, van Eijck CH, et al. Nurse-led follow-up at home vs. conventional medical outpatient clinic follow-up in patients with incurable upper gastrointestinal cancer: A randomized study. J Pain Symptom Manage 2014;47:518-30.

14. Zimmermann C, Swami N, Krzyzanowska M, et al. Early palliative care for patients with advanced cancer: A clusterrandomised controlled trial. Lancet 2014;383:1721-30.

15. :Ramsey SD, Fedorenko C, Chauhan R, et al. Baseline Estimates of Adherence to American Society of Clinical Oncology/American Board of Internal Medicine Choosing Wisely Initiative Among Patients With Cancer Enrolled With a Large Regional Commercial Health Insurer. J Oncol Pract 2015;11:338-43.
16. Rao V, Olszewski A, Egan P, et al. Billed palliative care services and end-of-life care in patients with hematologic malignancies. 2019 Supportive Care in Oncology Symposium. Presented October 26, 2019:abstr 43.

17. Steinmann D, Paelecke-Habermann Y, Geinitz H, et al. Prospective evaluation of quality of life effects in patients undergoing palliative radiotherapy for brain metastases. BMC Cancer 2012;12:283.

18. National Comprehensive Cancer Network. Central Nervous System Cancers (Version 3.2019). Accessed November 17, 2019. Available online: https://www.nccn. org/professionals/physician_gls/pdf/cns.pdf

19. Sperduto PW, Kased N, Roberge D, et al. Summary report on the graded prognostic assessment: An accurate and facile diagnosis-specific tool to estimate survival for patients with brain metastases. J Clin Oncol 2012;30:419-25.

20. Shaw E, Scott C, Souhami L, et al. Single dose radiosurgical treatment of recurrent previously irradiated primary brain tumors and brain metastases: final report of RTOG protocol 90-05. Int J Radiat Oncol Biol Phys 2000;47:291-8.

21. Temel JS, Greer JA, Muzikansky A, et al. Early palliative care for patients with metastatic non-small-cell lung cancer. N Engl J Med 2010;363:733-42.

22. Hui D, Kim SH, Roquemore J, et al. Impact of timing and setting of palliative care referral on quality of end-of-life care in cancer patients. Cancer 2014;120:1743-9.

23. Watson GA, Saunders J, Coate L. Evaluating the Time to Palliative Care Referrals in Patients With Small-Cell Lung Cancer: A Single-Centre Retrospective Review. Am J Hosp Palliat Care 2018;35:1426-32.

24. Smith CB, Nelson JE, Berman AR, et al. Lung cancer physicians' referral practices for palliative care consultation. Ann Oncol 2012;23:382-7.

25. Girard N, Cozzone D, de Leotoing L, et al. Extra cost of brain metastases (BM) in patients with non-squamous non-small cell lung cancer (NSCLC): a French national hospital database analysis. ESMO Open 2018;3:e000414.

26. Stavas M, Arneson K, Friedman J, et al. From Whole Brain to Hospice: Patterns of Care in Radiation Oncology. J Palliat Med 2014;17:662-6.

27. Greer JA, Pirl WF, Jackson VA, et al. Effect of early palliative care on chemotherapy use and end-of-life care in patients with metastatic non-small-cell lung cancer. J Clin Oncol 2012;30:394-400.

28. Teno JM, Gozalo P, Trivedi AN, et al. Site of death, place of care, and health care transitions among US Medicare 
beneficiaries, 2000-2015. JAMA 2018;320:264-71.

29. Accreditation Council for Graduate Medical Education. Accessed January 14, 2020. Available online: https://www. acgme.org

30. Pifer PM, Farrugia MK, and Mattes MD. Comparative analysis of the views of oncologic subspecialists and palliative/supportive care physicians regarding advanced care planning and end-of-life care. Am J Hosp Palliat Care 2018;35:1287-91.

31. Gross JP, Kruser J, Moran M, et al. Radiation Oncologists' role in end-of-life care: a perspective from medical oncologists. Pract Radiat Oncol 2019;9:362-70.

32. Cherny NI and Catane R. Attitudes of medical oncologists toward palliative care for patients with advanced and incurable cancer: report on a survey by the European society of medical oncology taskforce on palliative and supportive care. Cancer 2003;98:2502-10.

33. Wei RL, Mattes MD, Yu J, et al. Attitudes of radiation oncologists toward palliative and supportive care in the United States: Report on national membership survey by the American Society for Radiation Oncology (ASTRO). Pract Radiat Oncol 2017;7:113-9.

34. Mulvenna P, Nankivell M, Barton R, et al. Dexamethasone and supportive care with or without whole brain radiotherapy in treating patients with nonsmall cell lung cancer with brain metastases unsuitable for resection or stereotactic radiotherapy (QUARTZ):

Cite this article as: McDermott DM, Seldomridge A, Maniar A, Mattes MD. Patterns of palliative care consultation among patients with brain metastasis: an opportunity for radiation oncologists to facilitate earlier referral. Ann Palliat Med 2020;9(5):3513-3521. doi: 10.21037/apm-20-462 results from a phase 3 , non-inferiority, randomised trial. Lancet 2016;388:2004-14.

35. Kondziolka D, Parry PV, Lunsford LD, et al. The accuracy of predicting survival in individual patients with cancer. $\mathrm{J}$ Neurosurg 2014;120:24-30.

36. Hallenbeck J. Palliative Care Perspectives. Oxford, New York: Oxford University Press, 2003.

37. Gripp S, Moeller S, Bölke E, et al. Survival prediction in terminally ill cancer patients by clinical estimates, laboratory tests, and self-rated anxiety and depression. J Clin Oncol 2007;25:3313-20.

38. Viganò A, Dorgan M, Bruera E, et al. The relative accuracy of the clinical estimation of the duration of life for patients with end of life cancer. Cancer 1999;86:170-6.

39. Chow E, Davis L, Panzarella T, et al. Accuracy of survival prediction by palliative radiation oncologists. Int J Radiat Oncol Biol Phys 2005;61:870-3.

40. Chow E, Abdolell M, Panzarella T, et al. Validation of a predictive model for survival in metastatic cancer patients attending an outpatient palliative radiotherapy clinic. Int J Radiat Oncol Biol Phys 2009;73:280-7.

41. Morita T, Tsunoda J, Inoue S, et al. The palliative prognostic index: a scoring system for survival prediction of terminally ill cancer patients. Support Care Cancer 1999;7:128-33.

42. Parkes CM. Commentary: prognoses should be based on proved indices not intuition. BMJ 2000;320:473. 